\title{
SELECTION ASSOCIATED WITH THE ALCOHOL DEHYDROGENASE LOCUS IN DROSOPHILA MELANOGASTER: DIFFERENTIAL SURVIVAL OF ADULTS MAINTAINED ON LOW CONCENTRATIONS OF ETHANOL
}

\author{
KEVIN DALY and BRYAN CLARKE* \\ Department of Biology, California State University, Northridge, California 91330, U.S.A.; \\ *Genetics Research Unit, Queen's Medical Centre, Clifton Boulevard, Nottingham \\ NG7 $2 U H$
}

Received 10.vi.80

\section{SUMMARY}

\begin{abstract}
David and his collaborators have reported that adult Drosophila melanogaster survive longer on 2 per cent ethanol than on distilled water, but that the increased survival on ethanol does not occur in mutant flies lacking alcohol dehydrogenase activity. This has led us to onquire if the polymorphic alleles at the alcohol dehydrogenase locus $\left(A d h^{\mathrm{F}}\right.$ and $\left.A d h^{\mathrm{S}}\right)$, which code for enzymes with different activities, affect survival on low concentrations of ethanol. Flies were kept in sealed glass chambers containing either 2 per cent ethanol or distilled water. In four experiments, comprising a total of 126 replicates, the proportion of surviving FF flies, relative to SS, was greater on ethanol than on water. In two experiments the excess was highly significant. It appears that FF flies are better able than SS to use ethanol as food. Our results support the view that selection acts directly on the $A d h$ polymorphism.
\end{abstract}

\section{INTRODUCTION}

NEARLY all natural populations of Drosophila melanogaster are polymorphic at the alcohol dehydrogenase locus. The commonest alleles are "fast" $\left(A d h^{\mathrm{F}}\right)$ and "slow" $\left(A d h^{\mathrm{S}}\right)$, so named because of their electrophoretic mobilities at $p \mathrm{H} 8.6$ in a starch gel. The polymorphism has proved to be an excellent experimental system for studying the factors that influence gene frequencies in natural and artificial populations, and it has already provided strong evidence of selective differences between allozymes (see Clarke, 1975).

The "fast" protein $(A D H-\mathrm{F})$ differs from the "slow" $(A D H-\mathrm{S})$ by only a single amino acid (threonine for lysine; Thatcher, 1980). This substitution significantly alters the maximum velocity $\left(V_{\max }\right)$, affinity for substrate $\left(K_{m}\right)$, substrate specificity, and temperature stability of the enzyme, as well as its behaviour with inhibitors (Vigue and Johnson, 1973; Day et al., 1974; Thatcher unpublished). The biochemical differences between the allozymes are not concordant with the view that the amino-acid substitution is selectively neutral, but they do not by themselves refute it. In order to do so, it is necessary to demonstrate that the differences are detected by natural selection, in other words that they are reflected in differential survival or reproduction.

There is already evidence of such a relation. Several studies have shown that $A d h^{\mathrm{F}}$ homozygotes survive better than $A d h^{\mathrm{S}}$ on food with high 
concentrations ( $>10$ per cent) of ethanol (Birley, 1971: Briscoe et al., 1975; Morgan, 1975; van Delden et al. 1978). It is presumed that the F enzyme, which has approximately twice the $V_{\max }$ of the $\mathrm{S}$, is better able to detoxify ethanol. This presumption is supported by the fact that "null" mutant flies, with no $A D H$ activity, are killed by low concentrations ( $>4$ per cent) of the alcohol. Morgan (1975) found a correlation between the substrate specificities of the allozymes and their relative survival on different alcohols, an observation suggesting that the selection acts directly on the $A d h$ locus, rather than on other loci in linkage disequilibrium with it.

Recent studies by David and his collaborators (David et al., 1976; David, 1977) have suggested that $A D H$ has an additional role, making use of ethanol as food. It was found that a low concentration of ethanol can dramatically prolong the life of starving adult flies. Insects given a 2 per cent solution of ethanol survive more than twice as long as those given only water, but this lengthening does not occur with mutants lacking $A D H$ activity. A question that immediately arises is whether carriers of the more active $A D H-F$ enzyme are better able to use ethanol than those carrying the $A D H$-S enzyme. The present paper considers this question.

\section{MATERIAL AND METHODS}

The flies used in all the experiments came from cages containing subpopulations homozygous for the $A d h^{\mathrm{F}}$ and $A d h^{\mathrm{S}}$ alleles, derived from a stock originally collected in Kaduna, Nigeria, and maintained as a large $(2000+)$ laboratory population at Edinburgh University for more than thirty years. The Kaduna population contains no inversions, but remains polymorphic at the $A d h$ locus. The sub-populations were derived by making random crosses between Kaduna flies. After the eggs had been laid, the genotypes of the parents were established by electrophoresis. The offspring of heterozygote $\times$ homozygote matings were retained, and sib-mated. One homozygote $\times$ homozygote cross from each group of sib matings was kept, and established as a separate stock. In this way we obtained forty independent stocks homozygous for $A d h^{\mathrm{F}}$ and forty homozygous for $A d h^{\mathrm{S}}$. The stocks homozygous for each allele were then crossed among themselves in an orderly manner (i.e., $A \times B, C \times D$, etc., then $A B \times C D, E F \times G H$, and so on) until they had all been incorporated into one large population. The two populations so obtained were used as sources of the experimental material. The object of deriving the populations in this way was to minimise the possibility of creating linkage disequilibrium between the $A d h$ locus and other loci linked to it. We could not, of course, eliminate any linkage disequilibrium that might have existed in the original Kaduna population.

The adults used in experiments 1,2 and 3 were reared from medium in food-trays that had been put in the population cages. The trays contained a medium consisting of $1000 \mathrm{ml}$ water, $75 \mathrm{~g}$ maize-meal, $11 \mathrm{~g}$ dried dead yeast, $10 \mathrm{~g}$ agar, $2.5 \mathrm{~g}$ Nipagin, and $2.5 \mathrm{ml}$ propionic acid. The trays were taken from the cages, and the medium containing larvae apportioned among $\frac{1}{3}$-pint milk bottles containing fresh medium. When the adults emerged, the bottles were cleared of flies at 24-hour intervals. Before their exposure to the experimental conditions, the flies were allowed to age for 4-5 days in $30 \mathrm{ml}$ vials containing $10 \mathrm{ml}$ of medium. They were reared and maintained at approximately $22^{\circ} \mathrm{C}$. 
In the fourth experiment, the flies were allowed to lay eggs on plastic petri dishes $(15 \times 100 \mathrm{~mm})$ for a period of approximately 18 hours. The dishes, which contained the "standard" medium, were then incubated at approximately $28^{\circ} \mathrm{C}$. Newly-hatched first instar larvae were transferred to $30 \mathrm{ml}$ vials containing $10 \mathrm{ml}$ of high-yeast medium (identical to the standard medium except that it contained $50 \mathrm{~g}$ of dried yeast per litre). One hundred larvae were put in each vial. The vials were then kept at $22^{\circ} \mathrm{C}$. Adults were removed daily as they emerged. They were allowed to age for 4-5 days in $30 \mathrm{ml}$ vials containing standard medium. These additional precautions were taken because we found that the quantity of $A D H$ per adult fly can be greatly affected by the degree of crowding among larvae, and that differences in quantity between adults from replicate cultures are smaller in high-yeast medium than in standard medium (Clarke et al., 1979).

In order to discover the relative abilities of homozygous $A d h^{\mathrm{F}}$ and $A d h^{\mathrm{S}}$ flies to survive on water and 2 per cent ethanol, the adults were kept in chambers made of two $30 \mathrm{ml}$ vials joined at the mouth with a strip of masking tape. A ball of bleached cotton wool $(1 \mathrm{~g})$ was put in one of the vials, and covered by a disc of chromatography paper (Whatman No. $3 \mathrm{MM}$ ). Then $10 \mathrm{ml}$ of distilled water, or of a 2 per cent aqueous solution of ethanol, were added. Because we wished to score large numbers of replicates, and not to be limited by the time taken in electrophoresis, we set up the chambers in pairs, one containing ten male $A d h^{\mathrm{F}} / A d h^{\mathrm{F}}(\mathrm{FF})$ and ten female $A d h^{\mathrm{s}} / A d h^{\mathrm{s}}$ (SS) flies, the other containing ten male SS and ten female FF flies. The surviving genotypes could thus be identified by their sex, and the pairing of the chambers allowed us to correct for differential survival between the sexes. Each replicate involved four chambers, one pair with 2 per cent ethanol and one pair with distilled water. In the first experiment there were 22 replicates, in the second there were 26 , in the third 40 and in the fourth 38 , a total of 126 replicates in all. The chambers were kept at $22^{\circ} \mathrm{C}$, and observed daily until approximately 50 per cent of the flies in a chamber had died, when the numbers of surviving flies of each sex were counted. Because the flies kept on distilled water tended to die precipitately on the third or fourth day, the proportion of survivors in these chambers was usually well below 50 per cent when they were scored.

\section{Results}

The numbers and percentages of survivors are summarised in table 1. It can be seen that in every experiment the ratio of surviving FF flies to surviving SS flies was higher on ethanol than it was on water. This outcome would be expected if the more active enzyme possessed by the FF flies allowed them more effectively to use the ethanol as food.

There are differences in survival between experiments. Some of these are no doubt due to variations in the environmental conditions. The experiments were carried out at different times of the year and although the flies were grown in constant-temperature cabinets it was not possible exactly to control the humidity. In the first three experiments there may also have been uncontrolled variations in the degree of crowding, and hence in the quantity of $A D H$ (Clarke et al., 1979). These variations could affect one genotype more than the other. In the fourth experiment the degree of 
TABLE 1

The numbers of $\mathrm{Adh}^{F} / \mathrm{Adh}^{F}(F F)$ and $\mathrm{Adh}^{S} / \mathrm{Adh}^{S}(S S)$ Drosophila melanogaster adults surviving after being fed only on 2 per cent ethanol or only on distilled water

\begin{tabular}{|c|c|c|c|c|c|c|c|}
\hline \multirow[b]{2}{*}{ Experiment } & \multirow[b]{2}{*}{ Treatment } & \multirow{2}{*}{$\begin{array}{l}\text { Number of } \\
\text { flies } \\
\text { exposed }\end{array}$} & \multirow{2}{*}{$\begin{array}{c}A d h \\
\text { genotype }\end{array}$} & \multicolumn{3}{|c|}{$\begin{array}{c}\text { Number of flies } \\
\text { surviving }\end{array}$} & \multirow{2}{*}{$\begin{array}{c}\text { Percentage } \\
\text { survival }\end{array}$} \\
\hline & & & & १९ & 30 & Total & \\
\hline 1 & $\begin{array}{c}2 \% \text { ethanol } \\
\mathrm{H}_{2} \mathrm{O}\end{array}$ & $\begin{array}{l}440 \\
440 \\
440 \\
440\end{array}$ & $\begin{array}{l}\text { FF } \\
\text { SS } \\
\text { FF } \\
\text { SS }\end{array}$ & $\begin{array}{r}156 \\
134 \\
79 \\
131\end{array}$ & $\begin{array}{l}98 \\
80 \\
30 \\
39\end{array}$ & $\begin{array}{l}254 \\
214 \\
109 \\
170\end{array}$ & $\begin{array}{l}57 \cdot 8 \\
48 \cdot 6 \\
24 \cdot 8 \\
38 \cdot 6\end{array}$ \\
\hline 2 & $\begin{array}{c}2 \% \text { ethanol } \\
\mathrm{H}_{2} \mathrm{O}\end{array}$ & $\begin{array}{l}520 \\
520 \\
520 \\
520\end{array}$ & $\begin{array}{l}\text { FF } \\
\text { SS } \\
\text { FF } \\
\text { SS }\end{array}$ & $\begin{array}{r}152 \\
150 \\
80 \\
83\end{array}$ & $\begin{array}{r}116 \\
85 \\
81 \\
93\end{array}$ & $\begin{array}{l}268 \\
235 \\
161 \\
176\end{array}$ & $\begin{array}{l}51 \cdot 5 \\
45 \cdot 2 \\
31 \cdot 0 \\
33 \cdot 8\end{array}$ \\
\hline 3 & $\begin{array}{c}2 \% \text { ethanol } \\
\mathrm{H}_{2} \mathrm{O}\end{array}$ & $\begin{array}{l}800 \\
800 \\
800 \\
800\end{array}$ & $\begin{array}{l}\text { FF } \\
\text { SS } \\
\text { FF } \\
\text { SS }\end{array}$ & $\begin{array}{l}277 \\
308 \\
241 \\
275\end{array}$ & $\begin{array}{r}130 \\
146 \\
91 \\
131\end{array}$ & $\begin{array}{l}407 \\
454 \\
332 \\
406\end{array}$ & $\begin{array}{l}50 \cdot 8 \\
56 \cdot 8 \\
41 \cdot 5 \\
50 \cdot 8\end{array}$ \\
\hline 4 & $\begin{array}{c}2 \% \text { ethanol } \\
\mathrm{H}_{2} \mathrm{O}\end{array}$ & $\begin{array}{l}760 \\
760 \\
760 \\
760\end{array}$ & $\begin{array}{l}\text { FF } \\
\text { SS } \\
\text { FF } \\
\text { SS }\end{array}$ & $\begin{array}{l}188 \\
197 \\
130 \\
187\end{array}$ & $\begin{array}{l}138 \\
149 \\
119 \\
187\end{array}$ & $\begin{array}{l}326 \\
346 \\
249 \\
374\end{array}$ & $\begin{array}{l}42 \cdot 9 \\
45 \cdot 5 \\
32 \cdot 8 \\
49 \cdot 2\end{array}$ \\
\hline
\end{tabular}

crowding was controlled and the experiment is not therefore subject to this source of error.

The results from individual replicates are summarised in table 2 . It can be seen that out of 126 replicates, 84 showed an improvement in the relative survival of FF on ethanol, 38 showed a decline, and 4 showed no change. In the absence of any difference between genotypes, the two classes (FF showing a relative excess on ethanol $[+]$, and FF showing a relative deficiency on ethanol [-]), are expected to be equal in number. Because there is significant heterogeneity between experiments in the proportions of the classes $\left(\chi_{(3)}^{2}=14.3, p<0.001\right)$, and because the methods used in experiment 4 differed from those used in the other experiments, the data cannot legitimately be combined and tested together. It is more proper to consider and analyse each experiment independently. These analyses are shown in table 3, where the complete data from each experiment are fitted to a log-linear model (Everitt, 1977). The calculations were carried out using

TABLE 2

The results of individual replicates. Those in the $(+)$ column showed a relative excess of FF flies on ethanol, those in the $(-)$ column showed a relative deficiency, and those in the $(=)$ column showed no change

\begin{tabular}{ccrcc} 
Experiment & \multicolumn{4}{c}{ Numbers of replicates } \\
& + & - & $=$ & Totals \\
1 & 19 & 1 & 2 & 22 \\
2 & 17 & 9 & 0 & 26 \\
3 & 20 & 20 & 0 & 40 \\
4 & 28 & 8 & 2 & 38 \\
Totals & 84 & 38 & 4 & 126
\end{tabular}



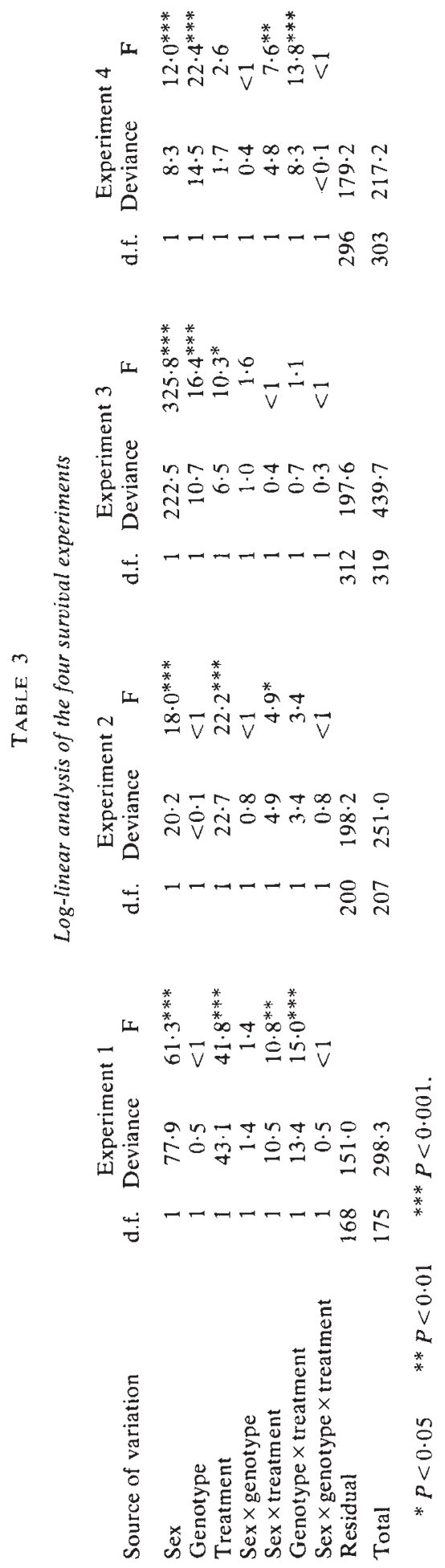
the GLIM program (Nelder, 1975) on the Nottingham University ICL 1906A computer.

Examining table 3, it can be seen from the row labelled "sex" that all experiments showed significant differences in survival between the sexes. The females survived better (table 1). The significant values in the row labelled "genotypes" are due to the fact that in the last two experiments the SS flies survived better overall than the FF. The values in the row labelled "treatment" merely indicate that the mortality is usually higher in the group given only water, for the reasons mentioned above. The next row shows that there is no interaction, as far as survival is concerned, between sex and genotype. There are, however, significant interactions between sex and treatment. As can be seen from table 1, ethanol appeared to reduce the proportion of females in experiment 1 , and to increase it in experiments 2 and 4 . In some laboratory cultures males have more $A D H$ than females, but in others the reverse is true (Clarke, unpublished observations). The factor causing these differences is unknown. It is certainly environmental, because reversals can occur in successive generations of the same stock.

The row labelled "genotype $\times$ treatment" is the one that is crucial to the present study. It shows that in experiments 1 and 4 the tendency for ethanol to improve the relative survival of FF flies was highly significant, that in experiment 2 it was nearly significant ( $p=0.067)$, and that in experiment 3 it was insignificant $(p=0.403)$. All experiments agreed in showing the same trend (see table 1), but particular weight should be given to the results of experiment 4 , in which the environment was the most strictly controlled.

\section{Discussion}

In all the experiments the ratio of surviving FF flies to surviving SS flies was higher on ethanol than on water. Before concluding that the FF flies were better able to use ethanol as food, it is necessary to consider some alternatives.

First, it might be argued that the findings are artifacts, because at the time of scoring those living on water had a lower average strvival (39.2 per cent) than those living on ethanol $(49.7$ per cent). If the two genotypes had survival curves of appropriate shapes (regardless of treatment) the difference in average survival could generate an apparent differential effect of ethanol. That this is not the correct explanation is indicated by a study of the replicates in which the proportion of flies surviving was higher on water than on ethanol, or was equal on the two treatments. There were 32 such cases, and of these 20 showed an increased relative proportion of FF on ethanol, 9 showed a decreased proportion, and 3 showed no change. The figures depart significantly from an expectation of equality $\left(\chi_{(1)}^{2}=4 \cdot 2, p<\right.$ $0 \cdot 05$ ), and in this case there is no heterogeneity between experiments. Thus the trend is not dependent upon a lower overall survival on water.

Second, it might be argued that we are observing not an improved metabolic use of ethanol by FF flies, but merely a higher toxicity of ethanol to SS. This argument is negated by the fact that SS flies survive far longer on 2 per cent ethanol than either of the genotypes survive on water (for example, in experiment 4 the average time taken by SS flies on ethanol to reach 42.9 per cent survival was $11 \cdot 0 \pm 0 \cdot 2$ days, and the average time taken by FF flies on water to reach 32.8 per cent survival was $3 \cdot 7 \pm 0 \cdot 1$ days). That the long 
survival of SS flies on ethanol is related to their ability to metabolise the alcohol is indicated by the fact that null flies survive no longer on ethanol than do SS flies on water, and that 2 per cent ethanol is not toxic even to nulls (David et al., 1976; David, 1977).

Third, it might be argued that the FF flies are non-specifically less resistant to stress, perhaps because of alleles in linkage disequilibrium with $A d h^{\mathrm{F}}$, and that consequently they suffer relatively higher mortality during starvation on water. We have already described the rather elaborate precautions taken to avoid the creation of linkage disequilibrium, but have noted that we could not eliminate any disequilibrium already existing in the Kaduna population. However, we know that Kaduna FF flies are not always less resistant to stress. They survive better when stressed by high concentrations of ethanol and other saturated alcohols (Morgan, 1975), and when stressed by crowding (Clarke, unpublished observations). Thus in order to make tenable the argument for non-specific stress it would be necessary to postulate ad hoc particular and special properties either of the $A d h$ locus, or of linked genes, properties for which we have no independent evidence.

Because it is possible that the method of obtaining the adults did not entirely remove environmentally-induced differences between FF and SS flies (which originated from different cages) the relative survivals of the two genotypes on either treatment by itself are likely to have little value. The important observation is the change in relative survival between experimentals (on ethanol) and controls (on water alone). Thus although overall there was a higher mortality of FF on water alone, we cannot conclude that this was due to some intrinsic property of FF flies. The causes may have been trivial. The significant fact is that there was a clear improvement in the relative survival of FF when they were given ethanol. In the light of what we know about the properties of $A D H$ it is realistic to suppose that the FF flies, by virtue of having an enzyme with a higher $V_{\max }$, are better able to make use of ethanol as food. We therefore regard the results of our experiments as evidence of selection acting directly on the polymorphism.

Acknowledgements.-We are grateful to the Science Research Council for financial support.

\section{REFERENCES}

BIRLEY, A. J. 1971. Selection modes in genetic polymorphisms. Ph.D. thesis, University College of Swansea.

BRISCOE, D. A., ROBERTSON, A., AND MAlpiCA, J. M. 1975. Dominance at $\boldsymbol{A} d \boldsymbol{h}$ locus in response of adult Drosophila melanogaster to environmental alcohol. Nature, 255, $148-149$.

CLARKE, B. 1975. The contribution of ecological genetics to evolutionary theory: detecting the direct effect of natural selection on particular polymorphic loci. Genetics, 79, 101-113.

CLARKE, B., CAMFIELD. R. G., GALVIN, A. M., AND PITTS, C. R. 1979. Environmental factors affecting the quantity of alcohol dehydrogenase in Drosophila melanogaster. Nature, 280, 517-518.

DAVID, J. R. 1977. Signification d'un polymorphisme enzymatique: la déshydrogénase alcoolique chez Drosophila melanogaster. Ann Biol., 16, 451-472.

DAVID, J. R., BOCQUET, C., ARENS, M. F.. AND FOUILLET, P. 1976. Biological role of alcohol dehydrogenase in the tolerance of Drosophila melanogaster to aliphatic alcohols: utilization of an $A D H$-null mutant. Biochem. Genet., 14, 989-997. 
DAY, T. H., HILlIER, P. C., AND CLARKE, B. 1974. The relative quantities and catalytic activities of enzymes produced by alleles at the alcohol dehydrogenase locus in Drosophila melanogaster. Biochem. Genet., 11, 155-165.

EVERITT, B. S. 1977. The Analysis of Contingency Tables. Chapman and Hall, London.

MORGAN, P. 1975. Selection acting directly on an enzyme polymorphism. Heredity, 34, 124-127.

NElder, J. A. 1975. GLIM Manual, Release 2, General Linear Interactive Modelling. Numerical Algorithms Group, 13 Banbury Road, Oxford.

THATCHER, D. R. 1980. The complete amino acid sequence of three alcohol dehydrogenase alleloenzymes $\left(A d h^{\mathrm{N}-11}, A d h^{\mathrm{S}}\right.$ and $\left.A d h^{\mathrm{UF}}\right)$ from the fruitfly Drosophila melanogaster. Biochem. J. 187, 875-886.

VAN DELDEN, W., BOEREMA, A. C., AND KAMPING, A. 1978. The alcohol dehydrogenase polymorphism in populations of Drosophila melanogaster. I. Selection in different environments. Genetics, 90, 161-191.

VIGUE, C. L., AND JOHNSON, F. M. 1973. Isozyme variability in species of the genus Drosophila. VI. Frequency-property-environment relationships of allelic alcohol dehydrogenases in D. melanogaster. Biochem. Genet., 9, 213-227. 